\title{
OBITUARIOS
}

\section{Dr. Alfredo Oscar López Alonso}

El 22 de abril de 2012 falleció el Dr. Alfredo López Alonso, investigador superior del Consejo Nacional de Investigaciones Científicas y Técnicas (CONICET) y miembro del Comité Editorial de INTERDISCIPLINARIA, desde su creación por el Dr. Horacio Rimoldi en 1980. Desde este lugar colaboró activamente, estando siempre dispuesto a ayudar con la lectura y crítica de artículos, atento a los objetivos de excelencia de INTERDISCIPLINARIA.

El Dr. López Alonso comenzó a trabajar en investigación en el Centro Interdisciplinario de Investigaciones en Psicología Matemática y Experimental (CIIPME), junto al Dr. Rimoldi que lo contó entre sus discípulos dilectos, de la misma manera que la Dra. Nuria Cortada. Comenzó justamente con el Dr. Rimoldi estudiando los efectos de anclaje en el escalamiento psicológico a través de los juicios condicionales, mostrando ya su interés en el efecto del contexto en la toma de decisiones de las personas. Más tarde se interesó en la definición de los estilos heurísticos y en el aprendizaje en la resolución de problemas con incertidumbre, que sería un primer paso hacia la temática en la que más se interesó y destacó que fue el estudio de la coherencia del razonamiento humano.

En 1981 dejó el CIIPME para ir a trabajar a la Universidad del Salvador donde inició el Instituto de Investigaciones Psicológicas del que fue Director durante muchos años. También ocupó el cargo de Vicedecano de la Facultad de Psicología y Psicopedagogía, así como el de Director del Doctorado en Psicología de la misma Universidad.

Una de sus primeras preocupaciones, que continuó durante toda su vida científica, fue conocer y transmitir los principios del método científico y la epistemología de la ciencia, convirtiéndose en un profundo estudioso en este campo. Ejerció una profusa labor docente, en especial en estadística, metodología de la investigación psicológica y estudio de los procesos. En los últimos años se había dedicado al área de la ecología de la mente y a la teoría de las representaciones sociales. Era un infatigable lector e incansable trabajador.

Su producción científica alcanza alrededor de 150 publicaciones en revistas prestigiosas de la especialidad, además de libros, capítulos de libros y numerosas presentaciones en congresos nacionales e internacionales.

Más allá de sus méritos como investigador y docente, fue nuestro compañero y amigo de muchos años. Siempre lo recordaremos. 
